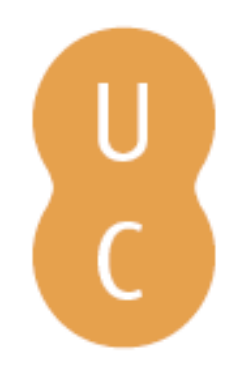

\title{
pompalina
}

\section{Releituras de um passado grego: a tragédia Oedipus Tyrannos de Sófocles}

Autor(es): $\quad$ Souza, Rogério José de

Publicado por: Associação Portuguesa de Estudos Clássicos; Imprensa da

Universidade de Coimbra

URL

persistente: URI:http://hdl.handle.net/10316.2/31826

DOI: $\quad$ DOI:http://dx.doi.org/10.14195/978-972-98142-2-8_13

Accessed : $\quad$ 26-Apr-2023 15:26:53

A navegação consulta e descarregamento dos títulos inseridos nas Bibliotecas Digitais UC Digitalis, UC Pombalina e UC Impactum, pressupõem a aceitação plena e sem reservas dos Termos e Condições de Uso destas Bibliotecas Digitais, disponíveis em https://digitalis.uc.pt/pt-pt/termos.

Conforme exposto nos referidos Termos e Condições de Uso, o descarregamento de títulos de acesso restrito requer uma licença válida de autorização devendo o utilizador aceder ao(s) documento(s) a partir de um endereço de IP da instituição detentora da supramencionada licença.

Ao utilizador é apenas permitido o descarregamento para uso pessoal, pelo que o emprego do(s) título(s) descarregado(s) para outro fim, designadamente comercial, carece de autorização do respetivo autor ou editor da obra.

Na medida em que todas as obras da UC Digitalis se encontram protegidas pelo Código do Direito de Autor e Direitos Conexos e demais legislação aplicável, toda a cópia, parcial ou total, deste documento, nos casos em que é legalmente admitida, deverá conter ou fazer-se acompanhar por este aviso.

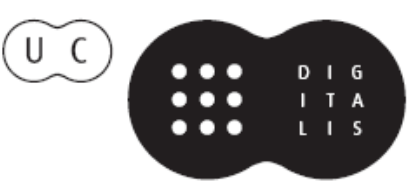




\section{Espaços e Paisagens}

\section{Antiguidade Clássica e Heranças Contemporâneas}

Vol. Il Línguas e Literaturas. Idade Média. Renascimento. Recepção

Francisco de Oliveira, Cláudia Teixeira, Paula Barata Dias (Coords.)

IMPRENSA DA UNIVERSIDADE DE COIMBRA 


\title{
RELEITURAS DE UM PASSADO GREGO A TRAGÉDIA OEDIPVS TYRANNOS DE SÓFOCLES
}

\author{
Rogério José DE SouZA ${ }^{\mathrm{I}}$ \\ Universidade Federal Rio de Janeiro
}

\begin{abstract}
In this analysis of the tragedy Oedipus Tyrannos, by Sophocles, the concern regards the issue of how a fragment that expresses an important characteristic, not only from the Polis but also from the Archaic period, is suppressed, becoming a common pattern to the various Portuguese language translators between the period of 1765 ( the oldest version found in Rio de Janeiro) and 2001 ( the last version found at afore mentioned city). This fragment refers to the description given by Jocasta to Laius, her husband and Oedipus' father. The passage (vv 740-745) refers to the moment the protagonist (Oedipus) asks his wife (Jocasta) to describe her deceased husband, Laius. The first word she uses, marks a physical characteristic of both characters. However, all the versions analysed, when compared to the English versions, omit or modify the sense in which the term referred to was known in the archaic Greek. Thus, we aim to demonstrate the close relationship between the omission/ modification of this fragment and the construction/ re-invention of an archaic Greek that, in the past, produced a very diverse documentation; the racialization seemed not to be so determinant, although during a later period, also rich in documentation, it seems to be diffused with racialized profile.
\end{abstract}

Keywords: epistemology, Greek tragedy, re-invention.

Palavras-chave: branquitude, epistemologia, reinvenção, tragédia grega.

Um dos eixos fundamentais no qual a produção conhecimento se alicerça está fundado na classificação social da população sobre a idéia de raça, uma realidade social que permeia as dimensões mais importantes das relações sociais brasileiras. Essa racialidade compreende também um certo número de aspectos que definem seu funcionamento em relação ao conjunto da sociedade. Nesse caso, o aspecto que nos interessa na discussão desse artigo é o fenômeno da branquitude.

$\mathrm{Na}$ historiografia, a hegemonia da branquidade é resultado de um longo processo de aprendizagem que se prolonga nas várias etapas de estudo da vida universitária. O cientista em formação é efetivamente isolado de outros interesses intelectuais ou vocacionais, ficando extremante dependente dos

${ }^{1}$ Mestre em História comparada pela UFRJ e pesquisador do Laboratório de História Antiga da UFRJ. 
seus professores. $\mathrm{O}$ professor tem uma efetiva influência sobre a escolha investigativa de um pesquisador iniciante, determinando se terá ou não sucesso na vida acadêmica, chegando, até mesmo ao conceito que o indivíduo faz de si mesmo.

Este modus operandi acadêmico nos leva a fazer a seguinte pergunta: como garantir a pluralidade dos temas investigados na universidade se existe uma ausência de professores negros, sobretudo em determinados campos de conhecimento? Esta ausência teria algum impacto na epistemologia da disciplina História? De fato o pequeno número de professores e estudantes negros nos programas de pós-graduação reflete na falta de pesquisas em determinados ramos do conhecimento. Cabe ressaltar que juntando todos os professores das principais universidades brasileiras (USP, UFRJ, UNICAMP, UNB, UFRGS, UFSCAR E UFMG) teremos um grupo de cerca de 18.400 acadêmicos, a maioria doutores. Deste universo, apenas setenta são negros, e nenhum é índio (Carvalho 2007: 93). Nesse sentido, não estaremos exagerando se afirmamos que a práxis historiográfica se confundiu com a ideologia da branquitude, mesmo que o método e a teoria pareçam seguir sem sofrer interferências. A invisibilidade ou ausência das discussões da ótica brancocentrada nos currículos escolares e universitários e a reprodução, circulação e influência em variados contextos sociais e pedagógicos tem assegurado um olhar unilateral em muitos campos das ciências humanas (Rossato; Y Gesser 2001: 32).

Melissa Steyn (2004: 115) se refere a branquidade como um "constructo ideológico do projeto modernista de colonização (...) um constructo de poder: os brancos, como grupo privilegiado, tomam sua identidade como a norma e o padrão pelos quais os outros grupos são medidos”. Este conceito se implica na produção teórica acadêmica, pois a autonomia da comunidade científica não pode ser tida como algo automático. A prática historiográfica está assentada em um sistema de referências e este sistema manifesta-se enquanto uma filosofia implícita particular que se mistura ao trabalho de análise, organizando-o à sua revelia, remetendo-o à subjetividade do autor (Certeau 1982: 67).

A historiografia como atividade humana multilateral não é só um corpo de conhecimentos ou teoria,é tambémuma metodologia, uma prática, uma tradição, e contém as formas de verificação, transmissão e absorção desse conhecimento. Além disso, a historiografia é uma olhar que permite importantes correlações e possui um poder simbólico. Segundo Bourdieu (1989), o poder simbólico consiste em um poder exercido através do discurso, reconhecido pelos demais e legitimado devido à posição social de quem o profere. No entanto, somente recebe prestígio ou poder simbólico quem detém capital simbólico, ou é capaz de transformar alguma espécie de capital, como por exemplo, capital econômico, cultural ou social, em capital simbólico.

Assim na historiografia falar-se-á que a subjetividade preside a escolha do objeto, sem evocar que a priori tem-se o discurso da cultura branca ocidental como a "única e verdadeira", em que o branco é o proprietário do lugar de referência (Said 1990). Sendo assim, as escolhas interpretativas que sigam outras direções estarão sujeitas a "polícia da historiografia" e ao tribunal presidido 
por um grupo que habilita ou não um locutor ao discurso historiográfico. Mas como ter a certeza de que pesquisadores negros e indígenas estão sendo academicamente avaliados, se não temos pares nas universidades? Como captar o lugar social do branco que avalia ou produz um trabalho e mensurar os limites epistemológicos que sua obra ou avaliação pode impor?

A historiografia é uma ciência implantada no seio da sociedade e como tal inevitavelmente passível de ser permeada pela ideologia da branquidade. Segundo César Rossato e Verônica Gesser (2001: 11),

\begin{abstract}
"a Branquidade seria uma consciência silenciada ou experiência branca e pode ser definida como uma forma sócio-histórica de consciência nascida das relaçôes capitalistas e leis coloniais, hoje compreendidas como relaçôes emergentes entre grupos dominantes e subordinados. Essa branquitude como geradora de conflitos raciais demarca concepções ideológicas, práticas sociais e formação cultural, identificadas com e para brancos como de ordem branca e, por conseqüência, socialmente hegemônica".
\end{abstract}

As lutas simbólicas estão sempre presentes no cotidiano, dissimuladas, entre os que têm interesse em manter as objetivações/representações oficiais e os que pretendem transformá-las. Revisitar os mitos fundadores da cultural ocidental e rever a retórica utilizada para legitimá-los na academia, contribuindo assim para o fim da legitimidade de procedimentos preconceituosos e discriminatórios no mundo acadêmico, uma vez que muitos dos argumentos de dominação, hierarquização são buscados em um passado forjado (Hobsbawn 1997: 10).

Sabemos que a "operação historiográfica" (Certeau 1982) viabiliza sempre um novo olhar sobre a história, o que pluraliza as considerações sobre um mesmo evento, mesmo quando analisado o passado que já se sabe, ou que se passou. $\mathrm{O}$ "fazer historiográfico" carrega em si o germe de sua contínua renovação, pois está sempre em andamento, numa investigação disposta a desvelar um fato ou personagem até que ambos se revelem em seus simulacros.

Não obstante, partindo das práticas e discursos historiográficos, Certeau (1982) se propõe a pensar algumas questões. Cabe citar uma delas para enriquecer as argumentações que justificam a relevância de nossas reflexões. $\mathrm{O}$ referido autor destaca a necessidade de se historicizar a História, que implica no movimento que liga uma prática interpretativa a uma prática social, e quanto essa preocupação é útil para pensar pesquisa e pesquisador (Certeau 1982: 33). Seguindo a profilaxia certeauniana, estamos sugerindo que a produção do conhecimento é indissociável das dinâmicas da branquitude presentes em nossa sociedade e este conhecimento está cada vez mais associado a equipes, profissionais de renome, financiamentos, e privilégios e prestígios que este ou aquele estudo proporcionam.

Deste ponto de vista, sendo a branquitude uma das norteadoras silenciosas das subjetividades que intercedem na escolha do objeto e ausente do status de prestígio de que dispõem outros recortes investigativos, como aumentar as produções que privilegiem outros grupos étnico-culturais? Como 
transversalizar estudos afro-brasileiros e africanos nos diferentes recortes temporais que compõem a prática historiográfica, saindo das circunscrições temáticas a que o negro está submetido no Brasil?

No que se refere às análises sobre a historiografia antiga, entrecruzá-las com o conceito de branquidade, buscando os princípios da branquidade nos leva a uma conclusão: o conjunto de convicções sobre a "brancura" ${ }^{2} \mathrm{da}$ Grécia Clássica e a conseqüente postura dos estudos clássicos brasileiros em refutar essa discussão, serviu como referencial para inclusão desse segmento de pesquisadores em uma categoria, que se percebia a si mesmo, a parte das transformações raciais verificadas na sociedade. Parece-nos que o fato de os estudos clássicos estarem em um passado longínquo e dependerem fundamentalmente das fontes escritas, iconografias etc, fizeram com que os intelectuais desse campo de estudo se pensassem transcendentes ao mundo cotidiano. Não se verificou o entrecruzamento entre as dinâmicas raciais brasileiras e a produção do conhecimento no campo da História Antiga no Brasil.

O "simulacro da branquidade" marca esses contextos historiográficos e têm orientado de forma sub-reptícia não só as estruturas sociais, como as formas de definição do conhecimento nelas produzidas. A branquitude nesse campo da historiografia personifica-se na força política obtida no esforço discursivo de silenciar a identidade branca presente na produção do conhecimento (Ware 2004; Apple 2001), pois o imaginário social está permeado pela idéia do branco como um padrão universal, neutro e destituído de racialidade.

Como parte dos elementos que apóiam este debate, analisar-se-á tragédia de Sófocles "Édipo Rei". O momento que interessa é a passagem em que o protagonista pede a Jocasta que descreva o finado rei Laios. Transcrevo aqui os versos (740-743) de Sófocles, tal como eles aparecem em grego na referida tragédia que chegou até dias atuais.

(Édipo) Não me interrogues. Antes quero que respondas: como era Laios e quantos anos tinha então?

(Jocasta) [Ele era] negro (mélas) e há pouco seus cabelos começaram a branquear. Sua aparência não era diferente da sua.

O termo mélas, apontado por Jocasta como uma característica de Laios, e, conseqüentemente, de Édipo, vem sendo omitido no português, desde pelo menos, 1785 até 2002, conforme dissertação defendida recentemente (Souza 2007: 13-15). Analisaremos as traduções mais recentes de três importantes

\footnotetext{
${ }^{2}$ Brancura aqui entendida como uma característica fenotípica, sendo um dos elementos definidores da identidade racial branca. Esta tem influência na definição das estratégias e produção discursiva desses grupos.
} 
intelectuais brasileiros. Como iremos verificar, todos os tradutores optam pelo termo mégas, ou seja, grande ao invés de mélas, ou seja, negro.

Como fonte de consulta para averiguação do significado do termo mélas foram utilizados quatro dicionários grego-português (ver item 2 da bibliografia). Todos eles traduzem a palavra como preto, negro.

Uma tradução da Tragédia de Édipo foi proposta por Mario da Gama Kury. Este acadêmico já havia publicado (1966), em prosa, uma outra tradução. Este trabalho tem uma preocupação acadêmica. $\mathrm{O}$ autor aponta, no prefácio, a quantidade de livros consultados para a realização da obra. Convém observar que ele foi uma das maiores autoridades do país em matéria de tradução de obras da Antigüidade grega. Entretanto, em ambas as obras, o termo mélas não conhece um sentido mais próximo da versão que aqui apresentamos.

(Édipo) Não me interrogues. Antes quero que respondas: Como era Laios e quantos anos tinha então?

(Jocasta) Ele era alto seus cabelos começavam a branquear Laios tinha traços teus.

Vejamos agora as traduções de 2000 e 2001, encontradas na Biblioteca Nacional no Rio de Janeiro. A primeira delas foi feita por Cegalla (2000), a partir de consultas às obras dos helenistas italiano Bassi e francês Gergin. O referido tradutor, embora seja um importante gramático da língua portuguesa e afirme traduzir diretamente do grego, mantém o mesmo padrão. Os diálogos traduzidos em nada se diferenciam dos anteriores:

(Édipo) Não me perguntes. Dize-me, antes, que aspecto físico e que idade tinham Laios? (Jocasta) Era alto, na cabeça apontavam-lhe os primeiros cabelos brancos. Fisicamente, era bastante parecido contigo.

A segunda tradução (2001) foi produzida por Vieira Trajano, professor de Letras Clássicas da UNICAMP. Esta obra tem caráter acadêmico e foi financiada pela FAPESP com apresentação de Jacó Guisburg, especialista em estética. O interessante é que na versão grega, em anexo da edição, o autor apresenta, na própria versão grega, a palavra mégas (alto), sem registrar uma nota de pé de página que aponte as possibilidades e ambigüidades da tradução do verso em questão. O diálogo mantém-se o mesmo:

(Édipo) Pergunta-me depois! Fala de Laios. Qual seu aspecto físico? Que idade tinha? (Jocasta) De porte grande, já com os fros grisalhos, os traços deles aos teus se assemelhavam".

As traduções e interpretações consagradas à tragédia de Sófocles "Édipo Rei” aparecem a cada ano num ritmo constante. No entanto, nenhuma das traduções analisadas registra em nota de pé de página a divergência em torno da tradução do termo em questão. $\mathrm{Na}$ versão em inglês que 
utilizamos como referência uma nota assinala a dúvida (e o mal-estar) do termo mélas no verso 742 .

A supressão do referido termo evidencia as dinâmicas do aspecto racial em razão de seu próprio silêncio, relacionado, portanto, a uma identidade ideológica derivada da branquitude. O silêncio tem um significado ideológico que repousa na omissão e se impõe como uma representação totalizante, funcionando como vetor da legitimidade do discurso branco. Como nos lembra Duby (1982), "é preciso interpretar o silêncio, pois há um significado ideológico que repousa na omissão".

A branquitude distorce a compreensão do passado grego, criando um falso consenso derivado de proximidade articular a uma identidade branca. Naturaliza-se uma informação, ou seja, um grupo de intelectuais emprega e confere legitimidade às categorias que fazem com que as formas ideológicas pareçam neutras, eliminando, ou deixando de problematizar, as contradições existentes no texto (Apple 1982: 65), isto é, o aparecimento do termo mélas.

Sob está ótica, de forma consciente ou inconsciente, identidades como negro, branco, mestiço não só existem, como estão associadas a hierarquias e lugares sociais correspondentes. Assim, a temporalização cria a possibilidade de tornar coerentes relações sociais fundadas na idéia de raça quando do estudo do passado clássico. A tradução da tragédia Édipo Tirano é um indício de que a historiografia, sobretudo aquela voltada para o campo da história antiga, autoriza a supressão da diferença pela ordem, reduzindo o elemento desconhecido a um erro dos copistas ou suprimindo aquilo que foge à explicação tradicional e nela assume aspecto de estranheza.

Nesse caso, a branquitude é o lugar da produção que autoriza e legitima o texto. $\mathrm{O}$ historiador supõe um passado já dado e esse se desvenda no seu texto, conforme percebemos na escolha do termo mégas e não mélas. Naturaliza-se, assim, uma imagem extremamente simplista de uma Grécia branca e ocidental, em que estão presentes às distinções ontológicas e epistemológicas entre "civilizados" (identificados aos brancos ocidentais) e "bárbaros" (africanos, árabes, asiáticos).

Há um modus operandi da branquidade na historiografia que tem conseqüências epistemológicas caras aos grupos étnicos raciais não-brancos. Como lócus de elaboração teórico-metodológica, a branquitude aparece nãodenominada ou denominada como "normativa" e a força de sua atuação é resultado do seu próprio ocultamento (Ware 2004: 324). Nesse sentido, tendo compreendido o processo social de construção da branquitude, enquanto interdito das produções acadêmicas no campo da historiografia, estaremos aptos a produzir uma literatura mais plural e que contemple distintos grupos étnicos-raciais. 


\section{Bibliografia}

\section{Traduções Utilizadas}

D. P. Cegalla (2000), Sófocles. Édipo Rei. Coleção Clássicos Gregos. Rio de Janeiro: Difel.

M. G. Kury (1998), A Trilogia Tebana (Édipo Rei, Édipo em Colono, Antígona). Rio de Janeiro: Zahar.

Sophocles (1984), Oedipus Tyrannus. Tradução: Robert Fagles. New York: Peguin Books, vv. 740-743.

Sophocles (1994), Oedipus Tyrannus. Tradução:Hugh Lloyd-Jones. Cambridge: Harvard University Press, vv. 740-743.

Sophocles (1994), Ajax, Electra, Oedipus Tyrannus. Cambridge: Harvard University Press (Loeb Classical Library).

T. Vieira (2001), Édipo Rei de Sófocles. São Paulo: FAPESP / Perspectiva.

\section{Trabalhos Específicos}

Michel Apple (1982), Ideologia e Currículo. São Paulo: Brasiliense.

Michael Apple (2001), Políticas de direita e branquidade: a presença ausente da raça nas reformas educacionais. Revista Brasileira de Educação. Rio de Janeiro, 16 61- 67.

Maria Aparecida Silva Bento (2003), Branqueamento e branquitude no Brasil. in: Iray Carone, Maria Aparecida Silva Bento (orgs.) Psicologia social do racismo: estudos sobre a branquitude e branqueamento no Brasil. Petrópolis: Vozes, 25-57.

M. Bernal (1987), Black Athena: The Afroasiatic Roots of Classical Civilisation. New Jersey: Rutgers University Press, vol. 1.

P. Bourdieu (1989). O poder simbólico. Lisboa: DIFEL

I. Carone e M. A. S. Bento (Orgs) (2002), Psicologia Social do Racismo: estudos sobre branquitude e branqueamento no Brasil. Rio de Janeiro: Vozes.

J. J. de Carvalho (2005), Inclusão étnica e racial no Brasil: a questão das cotas no ensino superior São Paulo: Attar.

M. Certeau (1982), A Escrita da Historia. Rio de Janeiro: Forense Universitária.

Jacques D’Adesky (2001), Pluralismo Étnico e Multiculturalismo. Racismo e Anti-Racismos no Brasil. Rio de Janeiro: Pallas.

Cheikh Anta Diop (1983), "Origem dos Antigos Egípcios", in G. Mokhtar (Org.). A Africa Antiga. Volume 2. São Paulo: Ática: Paris: UNESCO, 39-70.

G. Duby (1982), Historia Social e Ideologia da Sociedade. In: J. Le Goff, J. e P. Nora, (Org.) História: Novos Problemas. Rio de Janeiro: Francisco Alves. 
Enrique Dussel (2003), "Europa, modernidad y eurocentrismo”. in: Edgardo Lander (ed.) La colonialidad del saber : eurocentrismo y ciencias sociales, perspectivas latinoamericanas. Buenos Aires: Clacso.

Marc Ferro (1983), A manipulação da bistória no ensino e nos meios de comunicação. São Paulo: IBRASA.

Henry Giroux (1999), "Por uma pedagogia e política da branquidade". Cadernos de Pesquisa. São Paulo, 107, págs. 97-132.

Antônio Sérgio Alfredo Guimarães (1999), Racismo e Anti-Racismo no Brasil. São Paulo: FAPESP / editora 34.

Stuart Hall (2003), Da Diáspora: identidades e mediaçóes culturais. Belo Horizonte: Editora UFMG.

Eric Hobsbawm e Terence Ranger (1997), A invenção das tradições. Rio de Janeiro: Paz e Terra.

J. Ki-Zerbo (Org.) (1982), Historia Geral da África: Metodologia e PréHistória da África. Volume 1. São Paulo: Ática, 21-42.

Edgardo Lander (2003), La Colonialidad Del Saber: eurocentrismo y ciências sociales, perspectivas latinoamericanas. Buenos Aires: Clacso.

Philippe Poutignat e Jocelyne Streiff-Fenart (1998). Teorias da Etnicidade. São Paulo: Ed. UNESP.

Anibal Quijano (2003), "Colonialidad del poder, eurocentrismo y América Latina” In: Edgardo Lander (Ed.), La colonialidad del saber: eurocentrismo y ciencias sociales, perspectivas latinoamericanas. Buenos Aires: Clacso.

Cesar Rossato e Verônica Gesser (2001), “A Experiência da Branquitude Diante de Conflitos Raciais: estudos de realidades brasileiras e estadunidenses" In: Eliane dos Santos Cavalleiro (Org.) Racismo e anti-racismo na educação: repensando a nossa escola. São Paulo: Summus/Selo Negro.

Edward W. Said (1990), Orientalismo: O Oriente Como Invenção do Ocidente. São Paulo: Cia. das Letras.

Rogério José Souza (2007),Tragédia "Édipo Rei" de Sófocles. O que ela tem a nos dizer sobre relaçóes raciais no campo da bistoriografia Clássica brasileira, 2007. Dissertação (Mestrado em Historia Comparada) - Programa de Pós Graduação em Historia Comparada, Universidade Federal do Rio de Janeiro, Rio de Janeiro.

J. -P. Vernant e P. Vidal-Naquet (1997), Mito e Tragédia na Grécia Antiga. São Paulo: Duas Cidades.

Vron Ware (2004), Branquidade. Rio de Janeiro: Garamond. 